\title{
Construction and Validation of an Instrument to Measure Perceptions and Attitudes towards Genetically Modified Organisms in the Mexican Urban Population
}

\author{
Osval Antonio Montesinos-López ${ }^{1}$, Emeterio Franco-Pérez ${ }^{2}$, Kismiantini $^{3}$, Marco Alberto Valenzo Jiménez ${ }^{4}$, \\ Ignacio Luna Espinoza ${ }^{5}$, Laura Sanely Gaytan Lugo ${ }^{6} \&$ Sara Sandoval Carrillo ${ }^{1}$ \\ ${ }^{1}$ Faculty of Telematics, University of Colima, México \\ ${ }^{2}$ School of Marketing, University of Colima, México \\ ${ }^{3}$ Department of Mathematics, Yogyakarta State University, Indonesia \\ ${ }^{4}$ Faculty of Accounting and Administrative Sciences, Universidad Michoacana de San Nicolas de Hidalgo, \\ México \\ ${ }^{5}$ University of the Istmo, México \\ ${ }^{6}$ Faculty of Mechanical and Electrical Engineering, University of Colima, México \\ Correspondence: Osval Antonio Montesinos-López, Faculty of Telematics, University of Colima. Av. \\ Universidad 333, Col. Las Viboras, C.P. 28040, Colima, México. E-mail: oamontes1@ucol.mx
}

Received: February 21, 2020

Accepted: March 26, 2020

Online Published: April 15, 2020

doi:10.5539/ijbm.v15n5p83

URL: https://doi.org/10.5539/ijbm.v15n5p83

\begin{abstract}
Introduction: this paper presents the development and validation of an instrument to measure the perceptions and attitudes about the production and consumption of the Mexican urban consumers towards genetically modified organisms (GMOs). Method: The proposed questionnaire contains 63 questions that encompassed 11 latent factors that was applied to 14,720 people of the Mexican urban population aged between 18 to 65 years. This measuring questionnaire was validated using confirmatory factor analysis (CFA). Results: we found that it is acceptable the proposed instrument for measuring perceptions and attitudes towards genetically modified organisms (PAGMOs) for the urban Mexican population. Discussion and Conclusion: The same instrument (construct) it is suitable for each of the 8 regions studied since with the multi-group CFA performed we found evidence that this is valid for each of the regions under study. Also, the analysis of the questions of the proposed instrument revealed that participants have a low general knowledge, a high distrust towards GMOs, want labeling of genetically modified (GM) products and not perceive their social values and positive health effects beyond increasing agricultural productivity.
\end{abstract}

Keywords: Construction, validation, questionnaire, perceptions, attitudes, genetically modified organisms, confirmatory factor analysis

\section{Introduction}

Currently in the world several Genetic Engineering techniques are being developed and applied in

plants and animals to increase the production of food that is made with Genetically Modified Organisms (GMOs) in order to increase production and extend safety levels and reduce malnutrition in the population in poor and developing countries (Kimani \& Zennah, 2019). With the application of the genetic engineering methods in animals such as goats, cows, rabbits, and birds, the production costs of recombinant proteins used in medicine have been reduced through the use of milk, egg whites, blood and other body fluids (Woodfint, Hamlin, \& Lee, 2018). Consumer behavior has a higher level of distrust, in relation to the production and processing of foods with genetic engineering, considering the large number of diseases that are currently known. The buyer is afraid to consume food that can affect his family in the medium and long terms, as well as, the effects on the environment (Gatto \& Smoller, 2018). In the period from 1996 to 2019, crops with genetic engineering have been adopted by the commercial industry, by small and large farmers in industrialized and developing countries, however, this type of products and food are immersed in a great social controversy (Kamle M. , Kumar, Patra, \& Bajpai, 2017). In the last 23 years, more than 2.15 million hectares of biotech crops have been commercially 
cultivated in the world. Cultivating primarily: soybean, corn, cotton and canola, for a growing world population, it is estimated that by 2050 the world population will be 9,800 million. Therefore, it is required that a greater amount of nutritious and safe food be produced for good human nutrition (The International Service for the Acquisition of Agri-biotech Applications (ISAAA), 2017). Since 1996, when the cultivation of GMOs began, a great deal of controversy has been generated among the population around the world, with a large number of reports available in the media such as books, magazines, television, radio, newspapers and social networks. Some present the benefits of GMOs and others argue that have negative effects on the family and on future generations (Bardin, Perrissol, Facca, \& Smeding, 2017). In May 2016, the National Academies of Science, Engineering and Medicine (NASEM) published their report, "Genetic Engineering Crops". Participants in this meeting analyzed the risks, health benefits of humans and the effects on the environment of the GMOs (Landrum, Hallman, \& Jamieson, 2019). The conclusions of this meeting were as follows: there was not enough evidence of risks to human health and the environment between conventional crops and those of Genetic Engineering, these conclusions also were published in The New York Times (Pollack, 2016). However, a group of more than 300 independent scientists and academics disagrees with the conclusions in which some groups of researchers have stated doubts about the safety of crops and products made with genetic engineering, they mention that the conclusions lack scientific foundations, since no independent arbitrators have been reviewed (Hilbeck,et al., 2015). Knowledge of perceptions and attitudes towards biotechnology products are lacking in México, althougth various studies have been conducted in a large number of countries. Most surveys have an academic intention and the conclusions are only valid for specific regions (Pino, Amatulli, De Angelis, \& Peluso, 2016). Some important questionnaires to measure attitudes towards the production and consumption of GMOs have been constructed after a systematic literature review for specific regions as those proposed by Costa-Font and Gil (2009), Herodotou et al. (2012), Sorgo, Ambrozic-Dolinsek, Usak and Özel (2011) and Sorgo and Ambrozic-Dolinsek (2010). It is important to note, that those instruments were mostly designed for specific populations with a high skepticism towards transgenic and a moderate knowledge of biotechnology issues, which is characteristic of the European Community (Eurobarometer, 2010). In addition, there are also questionnaires that have been applied in contexts where populations have sympathy towards GMOs, such as Ma (2015). However, due to the peculiar characteristics of Mexican people, we propose to construct and validate a new questionnaire in order to measure their perceptions and attitudes toward GMOs. In Mexico, corn represents a biological and cultural heritage, for this reason GMOs introduction to México have generated a great controversy in the whole society causing mobilization of broad sectors of society (rural and urban) in defense of native seeds. Such protests have arisen not only because of the threat that agricultural biotechnology represents for native corn, but also because there is a need of more fair and sustainable options. These experiences seek to strengthen efforts to protect native maize. On the other hand, there are several opinions, which highlights the lack of knowledge about the advantages and disadvantages in terms of genetic, economic, social, cultural, public and ecological health (Reséndiz-Ramírez, López-Santillán, Briones-Encinia, Mendoza-Castillo, \& Varella-Fuentes, 2014).Therefore, it is important to construct and validate an instrument (1) to be able to understand the perceptions and attitudes of Mexican urban population about the production and consumption of GMOs, and (2) to study and assist decision-making about the introduction of transgenic in Mexico through a comprehensive analysis. Since there is no records about a questionnaire for measuring such perceptions and attitudes in Mexico, according to Sánchez and Echeverri (2004), in order to develop measurement scales, which are helpful in cases of complex measurement and with diffuse features, a process to validate an original questionnaire, which was based on existing instrument used in other countries, was implemented using confirmatory factor analysis (CFA), that is, a statistical technique used to assess measurement models, which represent hypotheses about relationships between indicators and factors.

\section{Method}

In this study our target population was the Mexican urban population aged between 18 to 65 years and the sample size at each region was obtained (Cochran, 1990; Olaiz-Fernández et al., 2006) with

$$
n=\frac{\left(Z_{\alpha / 2}\right)^{2}(1-p)(D E F F)}{r^{2}(p)(R R)(h)}
$$

This formula was used to estimate with a $90 \%$ confidence proportions close to $13 \%$ with a maximum relative error of about $17 \%$. The design effect (DEFF), expected response rate (RR), average number of people per household $(h)$ assumed were $2.84,75 \%$, and 1.29 respectively. $n$ denotes the households sample size, $p$ the proportion to estimate, $Z_{\alpha / 2}$ the quantile of a normal distribution, $r$ denotes the allowed relative error. With this formula we got a sample size of 1840 households per region. The size of the sample by region $(1,840$ households) was distributed proportional to the basic geostatistical area units (AGEBs) that make up the region. 
The selection of primary sampling units (PSU) is made up of the AGEBs listed in the 2010 Mexican census and the AGEBs of the 2010 census that are not listed in the 2010 census. Therefore, the selection of sample units was in several stages, at the first stage, the AGEBs within each location was selected, then blocks within each AGEB, then homes within each block and finally individuals within the households. The application of the questionnaire was done from May 21 to July 21, 2015 using questionnaire given in Table 2. Table 1 gives the distribution of the 14,720 surveys taken at national level. An adult aged between 18 to 65 years was selected at each household. Also, in each block was selected a household from each cardinal point. We found that $50.96 \%$ and $49.03 \%$ of the surveyed people were men and women, respectively. The largest participation was of people between 30 and 44 years (35.37\%), and the lowest of people between 45 and 54 (18.03\%).

Table 1. Sample size distribution by region in México.

\begin{tabular}{lllllll}
\hline Id & Region & Provinces & Locations & AGEBs & Blocks & People \\
\hline 1 & Mexico City & 1 & 13 & 98 & 500 & 1840 \\
2 & South Central & 4 & 19 & 98 & 547 & 1840 \\
3 & North Central & 3 & 14 & 103 & 511 & 1840 \\
4 & Northeastern & 3 & 17 & 100 & 504 & 1840 \\
5 & Western & 5 & 16 & 95 & 511 & 1840 \\
6 & South & 5 & 18 & 96 & 504 & 1840 \\
7 & Center & 5 & 19 & 94 & 505 & 1840 \\
8 & Northwest & 4 & 14 & 100 & 502 & 1840 \\
& National & 30 & 130 & 784 & 4084 & 14720 \\
\hline
\end{tabular}

Source (Montesinos-López, Franco-Pérez, Luna-Espinoza, \& Aragón-Cuevas, 2016).

With respect to occupation, homemaker was the most frequent (29.66\%), followed by services, trade and others with 19.72, 17.4 and $16.45 \%$, respectively, and then by manufacturing, construction, agriculture and transportation with 5.96, 4.6, 2.97 and $2.18 \%$, respectively. Finally, with less than $1 \%$, are livestock, fisheries, mining and forestry with $0.51,0.21,0.17$ and $0.12 \%$, respectively.

\subsection{Instrument}

The questionnaire was built on studies conducted in different countries, and contain factors that measure perceptions and attitudes towards the production and consumption of GMOs. It is composed of 11 such factors: Trust, Knowledge, Perceived Risks, Benefits, Attitude towards Technology, Religion, Attitude toward Gene Technology, Labelling, Attitude towards Buying, Societal Values, and Promotion.

First, we made a list of 84 items related to the above mentioned 11 dimensions (latent factors); measured with a Likert-type scale of 5-points $(1=$ strongly disagree, $2=$ disagree, $3=$ neither agree nor disagree, $4=$ agree, $5=$ strongly agree). Then we conducted a pilot study with this questionnaire with a group of 90 people over 18 years of age from Colima, México. The study showed that respondents found it difficult to answer the survey items. Also, we found a high percentage of respondents who knew nothing about the use of GMOs, and most of them opted for answering option 3 (neither agree nor disagree). Also, we noted that the questionnaire was too long as it took 30 minutes on average to answer it, and respondents were eager to complete the questionnaire. Based on the results of the pilot survey, the problematic items were rewritten to improve the style and content. In this way, the questionnaire was reduced from 84 to 60 questions and the response options were simplified to a dichotomous scale. We also added questions aimed at gathering demographic information (occupation, educational level, gender and age) and a section to record aspects of geo-referencing. This instrument was tested with 1000 people in Colima, Mexico, and we only found small details that needed to be corrected. Finally, we end up with the questionnaire given on Table 2, consisting of 11 factors and 63 items that measure the perceptions and attitudes of the Mexican urban population about GMOs. 
Table 2. Dimensions (Latent factors) and items to measure perceptions and attitudes about GMOs in the Mexican urban population (The original version of the questionnaire is in Spanish language)

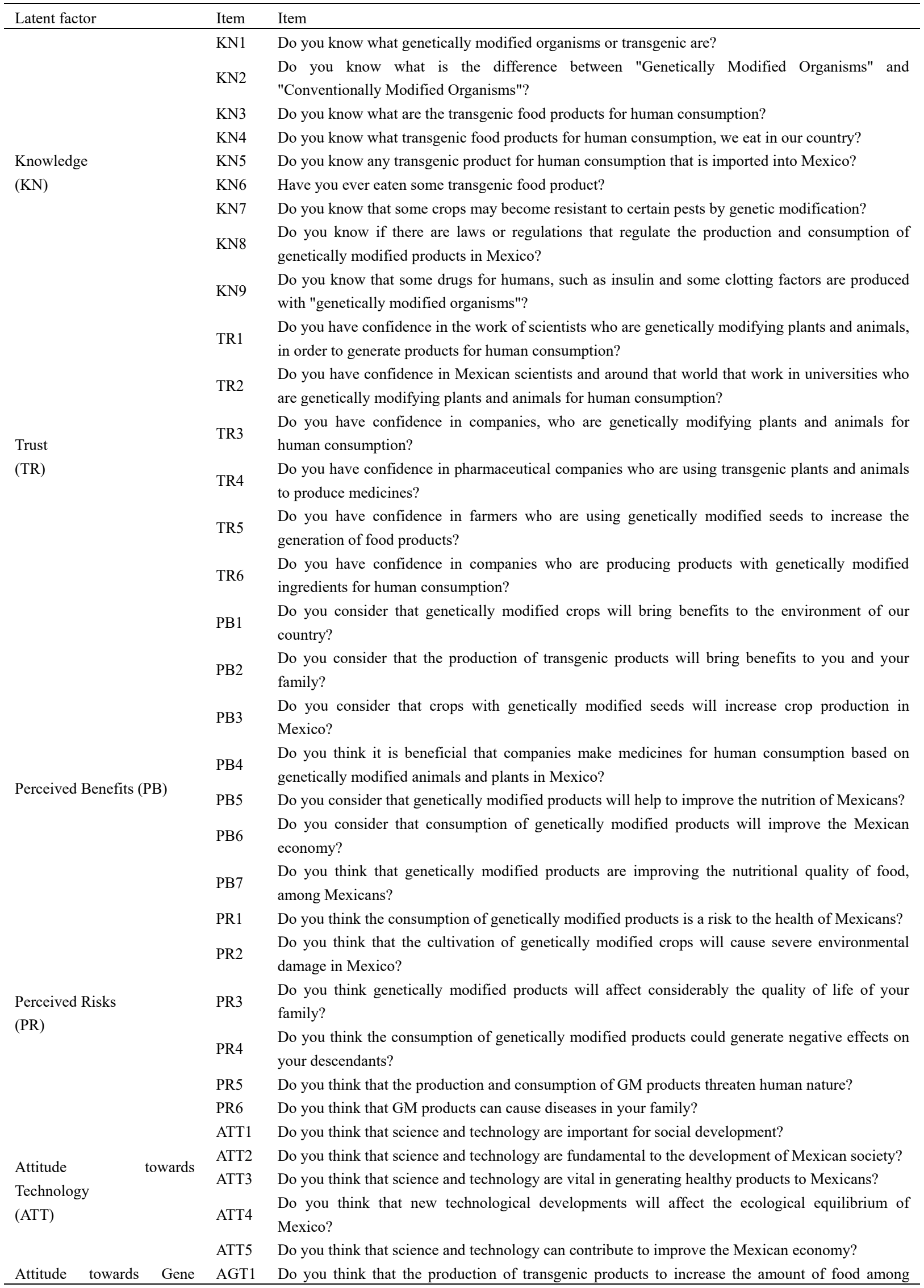




\begin{tabular}{|c|c|c|}
\hline \multirow[t]{8}{*}{ Technology (AGT) } & & Mexicans is a contribution? \\
\hline & AGT2 & $\begin{array}{l}\text { Do you consider morally acceptable the production of transgenic products for consumption by the } \\
\text { Mexicans? }\end{array}$ \\
\hline & AGT3 & $\begin{array}{l}\text { Do you agree with the production and consumption of transgenic products for the Mexican } \\
\text { population? }\end{array}$ \\
\hline & AGT4 & Do you think that transgenic products have higher nutritional content than organic products? \\
\hline & AGT5 & $\begin{array}{l}\text { Do you think the consumption of transgenic products will increase life expectancy of Mexican } \\
\text { society? }\end{array}$ \\
\hline & AGT6 & Do you agree in promoting transgenic products for family consumption? \\
\hline & REL1 & Does your religion is in favor of the development of transgenic products for human consumption? \\
\hline & REL2 & Does your religion prohibit the consumption of transgenic products? \\
\hline \multirow{4}{*}{$\begin{array}{l}\text { Religion } \\
\text { (REL) }\end{array}$} & REL3 & $\begin{array}{l}\text { Does your religion consider for moral reasons that you should not eat genetically modified } \\
\text { products? }\end{array}$ \\
\hline & REL4 & Does your religion consider morally incorrect the processing of transgenic products? \\
\hline & REL5 & $\begin{array}{l}\text { Is it right for your religion that scientists genetically modify plants and animals for human } \\
\text { consumption? }\end{array}$ \\
\hline & LA1 & $\begin{array}{l}\text { Do you have the habit of reading the labels of the products that your family consumes in the diet } \\
\text { before buying? }\end{array}$ \\
\hline \multirow{4}{*}{$\begin{array}{l}\text { Labelling } \\
\text { (LA) }\end{array}$} & LA2 & $\begin{array}{l}\text { Do you think that transgenic products must display on its label if they contain genetically modified } \\
\text { ingredients? }\end{array}$ \\
\hline & LA3 & $\begin{array}{l}\text { Do you think that in advertising of genetically modified products is vital that the consumer is } \\
\text { informed about the content of the product in question? }\end{array}$ \\
\hline & LA4 & $\begin{array}{l}\text { Do you think that the Mexican government should create laws to regulate the labeling of transgenic } \\
\text { products? }\end{array}$ \\
\hline & SV1 & Do you agree to consume transgenic products with your family? \\
\hline \multirow[t]{5}{*}{ Societal Values (SV) } & SV2 & $\begin{array}{l}\text { Do you agree that genetic technology can be used in the production of transgenic products for } \\
\text { human consumption? }\end{array}$ \\
\hline & SV3 & Do you think that transgenic products can help in the fight against hunger of Mexicans? \\
\hline & SV4 & Do you think that genetic technology solves the lack of food for Mexican society? \\
\hline & $\mathrm{AB} 1$ & Would you buy transgenic products if they contain less fat than conventional products? \\
\hline & $\mathrm{AB} 2$ & Would you buy transgenic products if they were cheaper than organic products? \\
\hline $\begin{array}{l}\text { Attitude } \\
\text { towards }\end{array}$ & $\mathrm{AB} 3$ & $\begin{array}{l}\text { Would you buy transgenic products if these were grown under similar environmental conditions to } \\
\text { the organic production? }\end{array}$ \\
\hline Buying & AB4 & Would you buy transgenic products if the price is equal to the organic products? \\
\hline \multirow[t]{4}{*}{ (AB) } & AB5 & $\begin{array}{l}\text { Would you buy a kilo of tortillas made with transgenic maize if the price is equal to a kilogram } \\
\text { made with conventional maize? }\end{array}$ \\
\hline & AB6 & Would you buy a kilogram of transgenic beans if the conventional kilogram of beans cost the same? \\
\hline & PN1 & $\begin{array}{l}\text { Do you agree that the Mexican government allows the production and consumption of transgenic } \\
\text { products? }\end{array}$ \\
\hline & PN2 & $\begin{array}{l}\text { Do you agree that the Mexican government support economically businesses to produce transgenic } \\
\text { products? }\end{array}$ \\
\hline \multirow[t]{3}{*}{$\begin{array}{l}\text { Promotion } \\
(\mathrm{PN})\end{array}$} & PN3 & $\begin{array}{l}\text { Would you agree that the Mexican government provides funding to public research institutes for the } \\
\text { development of transgenic products? }\end{array}$ \\
\hline & PN4 & $\begin{array}{l}\text { Would you agree that the Mexican government provides funding to conduct scientific research in } \\
\text { order to create transgenic drugs? }\end{array}$ \\
\hline & PN5 & $\begin{array}{l}\text { Would you agree that the government allows production and importation of biotech crop products } \\
\text { for consumption by the Mexicans? }\end{array}$ \\
\hline
\end{tabular}

Source: (Montesinos-López et al., 2016).

The hypothetical relationship between indicators and the factors given in Table 2 is shown in Figure 1. The first coefficient (load) of each factor was set to 1 to ensure an over-identified model (with more observations than parameters to estimate). This model also allows correlated factors. Fifty five correlations or covariance's were established because it has eleven factors. This model is over-identified (more observations than parameters to estimate) since the number of observations is larger than the number of parameters. Sixty three indicators gives $63((63+1)) / 2=2016$ number of observations. There were 175 parameters (49 loads factors, 11 variances of 
the factors, 60 thresholds and 55 covariance's between factors) to be estimated. Therefore, the degrees of freedom to test this model were 1841. When items are categorical, thresholds are required to obtain estimates of each of the categories of the responses. Since our response is binary, therefore only a threshold is used for each categorical item (Kismiantini, Montesinos-López, García, \& Franco-Pérez, 2014). Given the hypothetical model in Figure 1, we tested its credibility based on the data described above using the CFA for binary items.

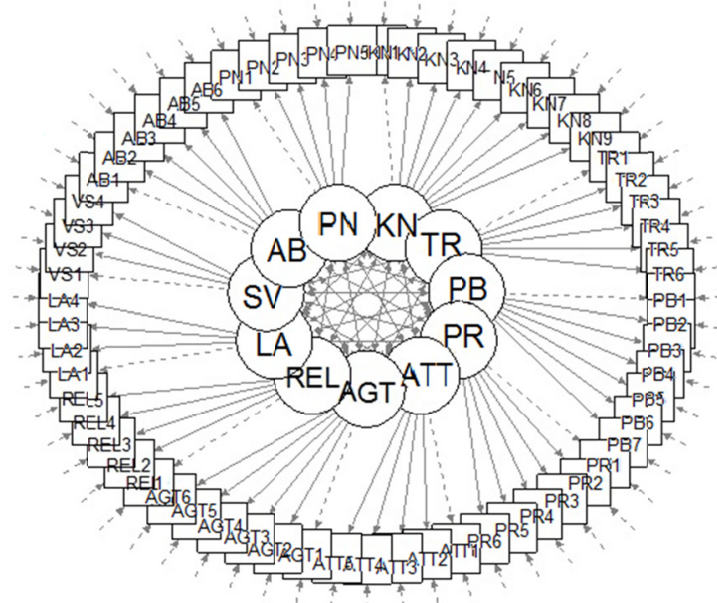

Figure 1. Hypothetical representation of the relationships between the latent factors and items to measure perceptions and attitudes of the Mexican urban population about GMOs

Source: (Montesinos-López et al. 2016).

Figure 1 is a schematic representation showing a concise overview of the hypothetical model that we want to validate, to measure the phenomena under study. It includes 63 observed (manifest) indicators (represented by rectangular boxes) and 11 latent variables (unobserved variables) represented by circles. Lines are used to indicate the relationships between variables (observed or unobserved). Single arrow lines represent a hypothesized direct relationship, in which the variable with the arrow pointing to is the dependent variable, while, double arrow lines indicate correlated variables. The proportions of error and unexplained variances for each observed indicator is indicated by arrows without origin. Also, all items are assumed independent of each other, since there are not two-way arrows between indicators.

\section{Analysis}

\subsection{Confirmatory Factor Analysis}

CFA is used to evaluate the factor (latent) structure of a set of observed variables. It allows the researcher to test a hypothetical model as that given in Figure 1 where a very well defined relationship between observed variables and their underlying latent constructs exists. Basically the theoretical model assumed (Figure 1) is compared with the observed structure in a sample (in this case the sample of 14,720 surveys taken nationally). The researcher uses knowledge of the theory, empirical research, or both, to postulate the relationship pattern a priori and then test the hypothesis statistically (Suhr, 2006; Kline, 2011). The factors or latent constructs are assumed to cause the observed scores in the indicators. Also, this technique is used for measurement invariance that means testing for equivalence of measures and the Multi-groups CFA (MGCFA) is the most useful approach to explore the validity of the proposed models between two or more groups. The verification of measurement invariance is important since it is a prerequisite for meaningful comparisons across groups, because guaranty that the same construct (or phenomena) is being measured in all groups.

The proposed questionnaire given in Table 2 and Figure 1 is composed of 11 factors (or latent variables) that cannot be measured directly for this reason we proposed 63 items to measure indirectly these 11 factors. However, to meaningfully compare the proposed latent variable across the 8 regions under study, each observed indicator must relate to its corresponding latent variable in the same way in all regions (groups). For this reason, we will test the measurement invariance across groups. Under the MGCFA approach for testing measurement invariance across groups one popular strategy to follow consist in organizing nested models in a hierarchical ordering with a decreasing number of parameters (or viceversa) through adding parameter constrains one at a time. These restricted models are tested in terms of their fit of the data to the model. Seven models are suggested 
for testing invariance and next we explain these models:

Configural invariance (Model 1). This is tested by constraining the factorial structure to be the same across groups and it is satisfied if the basic model structure is invariant across groups, indicating that participants from different groups conceptualize the constructs in the same way. This model is the first step to establish measurement invariance. Also, by running individual CFAs in each group configural invariance can be tested, but usually this approach is not used since it is still required to run this step in MGCFA, since it serves as the baseline model for subsequent tests.

Metric invariance (Model 2). This model is tested by constraining all factor loadings to be the same across groups. If this is satisfied, the ratings can be compared across groups and observed item differences will indicate group differences in the underlying latent construct. This model tests if the strengths of the relations between specific scale items and their respective underlying construct are the same across groups. At least partial metric invariance must be established before continuing in the sequence of tests (Vandenberg and Lance, 2000).

Scalar invariance (Model 3). To compare (latent) means it is required the scalar or intercept invariance. This model is evaluated by constraining the intercepts of items to be the same across groups. Establishing scalar invariance means that observed scores are related to the latent scores; that is, that regardless of their group membership individuals who have the same score on the latent construct would obtain the same score on the observed variable. To compare scores across groups this is the last model necessary. The additional tests are not mandatory since are not meaningful in all contexts.

Error variance invariance (Model 4). Here all error variances are constrained to be equal across groups to be able to test if the same level of measurement error is present for each item between groups.

Factor variance invariance (Model 5). This model is evaluated by constraining all factor variances to be the same across groups. This invariance means that the range of scores on a latent factor do not vary across groups.

Factor covariance invariance (Model 6). This model is evaluated by constraining all factor covariance's to be the same across groups. The stability of the latent factor relationships across groups is assessed in this model, which implies that all latent variables have the same relationship in all groups.

Factor mean invariance (Model 7). This model is evaluated by constraining the means to be the same across groups, which indicates that groups differ on the underlying construct(s).

The first 4 models evaluated measurement invariance because these models test relationships between measured variables and latent constructs. While models 5,6 and 7 test structural invariance and this models concern only the latent variables. The factor mean invariance can be tested (see Model 7 below) immediately after testing Model 3 (scalar invariance or intercept) since these models are not necessarily nested (Kline 2011). The CFA analysis was conducted in the R statistical package (R Core Team, 2015) with the library lavaan (Rosseel, 2012).

\subsection{Goodness-of-Fit Indices}

CFA model fit can be tested through chi-square analysis. A non-signicant chi-square is indication of good fit, that is, a non-significant chi-square value indicate a good fit. However, chi-square test is more sensitive with a larger sample size. Some authors suggest that the weighted root mean square residual (WRMR) index can be used to fit categorical data (WRMR $<1.0$ indicates a good fit) instead of the Standardized Root Mean Square Residual (SRMR) (Yu and Muthén, 2002). Hu and Bentler (1999) recommended using several fit indices. For this reason, in this paper we used three indices. We used the Tucker-Lewis index (TLI), the root mean square error of approximation (RMSEA) and the comparative fit index (CFI). The CFI and TLI evaluates the adequacy of the specified model in relation to the baseline model (Wade et al. 1996). Better fits are indicated by higher values (to a maximum of 1). Therefore, acceptable adjustments are considered with values $\geq 0.96$ for CFI and TLI (Yu, 2002). Compared to a perfect or saturated model the RMSEA estimates the lack of fit in a model (Steiger and Lind, 1980). A value below 0.06 for RMSEA provides an acceptable model fit (Browne and Cudeck, 1993).

Three specific incremental indices, based on the differences in the CFI, for testing measurement invariance has been suggested (Cheung and Rensvold, 2002) these are: (a) the Steiger's (1989) index (b) the gamma hat (GH) index; and the (b) McDonald's (1989) non-centrality index (NCI) that is obtained when comparing nested models.

The more restrictive model should be rejected If in the sequence of the invariance tests, two nested models show a decrease in the value of CFI, GH and NCI greater than or equal to .01, .01, and .02 in magnitude, respectively (Cheung and Rensvold, 2002). Here, we used the CFI, TLI, RMSEA and only the differences in the CFI since the other two indices are not given as output in the lavaan package we used for fitting our models. 


\subsection{Logistic Regression}

The logistic regression was used to test the factor mean invariance. For this reason, in each factor each item was considered as binary dependend variable (where $0=$ no and $1=y e s$ ) and the 8 regions under study were considered the independent variable. This associative analysis was key to see differences between regions on the perceptions and attitudes toward GMOs. We used the logistic regression since our dependent response variable is binary (see Stroup, 2012 for details of logistic regression).

\section{Results}

\subsection{Validation of the Measuring Instrument}

\subsubsection{Model Fit of the Single Group (at National Level) with CFA}

To validate the proposed questionnaire given in Figure 1 and Table 2, we performed a CFA for binary responses. The overall fit was satisfactory, because the CFI $=0.989(>0.96)$, TLI $=0.988(>0.96)$ and RMSEA $=0.055$ $(<0.06)$. Table 3 shows the factor loadings and thresholds for the model using CFA. All factor loadings were statistically significant ( $p$-value $<0.05$ ) and only one of the thresholds PN1 was not significant ( $p$-value $=0.574$ ). The largest variances of the factors correspond to factors: AB (6.869), TR (9.435) and PN (19.116), while the lowest correspond to factors: AGT (0.857) and LA (0.302) respectively. The maximum and minimum correlations values found between the eleven factors were 0.817 and -0.546 respectively. The largest positive correlations $(>0.75)$ of the factors were observed by pairs of factors; AGT-PB, LA-PB, SV-PB, SV-AGT, AB-SV and PN-SV with $0.817,0.756,0.756,0.795,0.767$ and 0.785 , respectively. These correlations suggest that; high perceived benefits (PB) are associated with a positive attitude towards gene technology (AGT), high societal values (SV) and a positive attitude towards labeling (ET). Also, high societal values are associated with a positive attitude towards gene technology (AGT), buying (AB) and high perceived risks (RP). Similarly, the highest negative correlations $(<-0.5)$ were obtained by the factor pairs: PR-PB, AGT-PR and PN-PR with -0.515 , -0.546 and -0.514 , respectively. These correlations indicate that high perceived risks (PR) are associated with low perceived benefits (PB), a negative attitude towards gene technology (AGT) and a negative attitude towards the promotion $(\mathrm{PN})$. Finally, the rest of correlations were closer to zero and for this reason are not reported.

Table 3. Estimation loadings and thresholds for the proposed model, using the CFA

\begin{tabular}{cccccccccc}
\hline Indicator & Factor & Standardized & \multicolumn{3}{c}{ Non-standardized loads } & \multicolumn{2}{c}{ Standardized } & \multicolumn{3}{c}{ Non-standardized thresholds } \\
& & loads & Value & S.E. & p-value & thresholds & Value & S.E. & p-value \\
\hline KN1 & KN & 0.898 & 1.000 & - & - & 0.220 & 0.499 & 0.025 & $<0.001$ \\
KN2 & & 0.855 & 0.807 & 0.023 & $<0.001$ & 0.670 & 1.290 & 0.027 & $<0.001$ \\
KN3 & & 0.965 & 1.805 & 0.070 & $<0.001$ & 0.318 & 1.213 & 0.052 & $<0.001$ \\
KN4 & & 0.962 & 1.726 & 0.063 & $<0.001$ & 0.358 & 1.310 & 0.052 & $<0.001$ \\
KN5 & & 0.844 & 0.773 & 0.022 & $<0.001$ & 0.647 & 1.209 & 0.025 & $<0.001$ \\
KN6 & & 0.848 & 0.786 & 0.022 & $<0.001$ & 0.234 & 0.441 & 0.020 & $<0.001$ \\
KN7 & & 0.717 & 0.504 & 0.014 & $<0.001$ & 0.117 & 0.168 & 0.015 & $<0.001$ \\
KN8 & & 0.600 & 0.368 & 0.012 & $<0.001$ & 0.873 & 1.092 & 0.017 & $<0.001$ \\
KN9 & & 0.628 & 0.396 & 0.012 & $<0.001$ & 0.667 & 0.857 & 0.016 & $<0.001$ \\
TR1 & TR & 0.951 & 1.000 & - & - & 0.026 & 0.084 & 0.034 & 0.013 \\
TR2 & & 0.948 & 0.971 & 0.046 & $<0.001$ & -0.063 & -0.198 & 0.033 & $<0.001$ \\
TR3 & & 0.939 & 0.887 & 0.037 & $<0.001$ & 0.296 & 0.859 & 0.037 & $<0.001$ \\
TR4 & & 0.884 & 0.615 & 0.024 & $<0.001$ & 0.086 & 0.184 & 0.022 & $<0.001$ \\
TR5 & & 0.911 & 0.720 & 0.030 & $<0.001$ & 0.036 & 0.087 & 0.025 & 0.001 \\
TR6 & & 0.949 & 0.985 & 0.047 & $<0.001$ & 0.338 & 1.079 & 0.048 & $<0.001$ \\
PB1 & PB & 0.851 & 1.000 & - & - & 0.293 & 0.557 & 0.022 & $<0.001$ \\
PB2 & & 0.920 & 1.452 & 0.05 & $<0.001$ & 0.331 & 0.845 & 0.034 & $<0.001$ \\
PB3 & & 0.716 & 0.634 & 0.019 & $<0.001$ & -0.337 & -0.483 & 0.016 & $<0.001$ \\
PB4 & & 0.845 & 0.975 & 0.031 & $<0.001$ & 0.121 & 0.227 & 0.020 & $<0.001$ \\
PB5 & & 0.916 & 1.414 & 0.049 & $<0.001$ & 0.334 & 0.836 & 0.032 & $<0.001$ \\
PB6 & & 0.749 & 0.699 & 0.021 & $<0.001$ & 0.150 & 0.227 & 0.016 & $<0.001$ \\
PB7 & & 0.927 & 1.521 & 0.056 & $<0.001$ & 0.401 & 1.065 & 0.039 & $<0.001$ \\
PR1 & PR & 0.889 & 1.000 & - & - & -0.300 & -0.655 & 0.027 & $<0.001$ \\
PR2 & & 0.889 & 0.998 & 0.037 & $<0.001$ & -0.110 & -0.240 & 0.023 & $<0.001$ \\
\hline
\end{tabular}




\begin{tabular}{|c|c|c|c|c|c|c|c|c|c|}
\hline PR3 & & 0.928 & 1.277 & 0.050 & $<0.001$ & -0.172 & -0.461 & 0.030 & $<0.001$ \\
\hline PR4 & & 0.945 & 1.487 & 0.060 & $<0.001$ & -0.243 & -0.742 & 0.037 & $<0.001$ \\
\hline PR5 & & 0.922 & 1.229 & 0.047 & $<0.001$ & -0.113 & -0.292 & 0.028 & $<0.001$ \\
\hline PR6 & & 0.955 & 1.649 & 0.074 & $<0.001$ & -0.357 & -1.199 & 0.053 & $<0.001$ \\
\hline ATT1 & ATT & 0.925 & 1.000 & - & - & -1.338 & -3.517 & 0.217 & $<0.001$ \\
\hline ATT2 & & 0.908 & 0.892 & 0.091 & $<0.001$ & -1.133 & -2.705 & 0.115 & $<0.001$ \\
\hline ATT3 & & 0.851 & 0.668 & 0.057 & $<0.001$ & -0.821 & -1.566 & 0.050 & $<0.001$ \\
\hline ATT4 & & -0.080 & -0.033 & 0.008 & $<0.001$ & -0.430 & -0.431 & 0.011 & $<0.001$ \\
\hline ATT5 & & 0.770 & 0.496 & 0.041 & $<0.001$ & -0.674 & -1.056 & 0.029 & $<0.001$ \\
\hline AGT1 & AGT & 0.679 & 1.000 & - & - & -0.279 & -0.380 & 0.015 & $<0.001$ \\
\hline AGT2 & & 0.907 & 2.327 & 0.072 & $<0.001$ & 0.179 & 0.425 & 0.026 & $<0.001$ \\
\hline AGT3 & & 0.964 & 3.938 & 0.186 & $<0.001$ & 0.144 & 0.543 & 0.045 & $<0.001$ \\
\hline AGT4 & & 0.81 & 1.491 & 0.045 & $<0.001$ & 0.580 & 0.989 & 0.022 & $<0.001$ \\
\hline AGT5 & & 0.825 & 1.578 & 0.047 & $<0.001$ & 0.520 & 0.921 & 0.023 & $<0.001$ \\
\hline AGT6 & & 0.959 & 3.644 & 0.178 & $<0.001$ & 0.360 & 1.266 & 0.063 & $<0.001$ \\
\hline REL1 & REL & 0.892 & 1 & - & - & 0.783 & 1.731 & 0.138 & $<0.001$ \\
\hline REL2 & & -0.716 & -0.521 & 0.058 & $<0.001$ & 1.310 & 1.878 & 0.032 & $<0.001$ \\
\hline REL3 & & -0.927 & -1.256 & 0.147 & $<0.001$ & 1.119 & 2.986 & 0.140 & $<0.001$ \\
\hline REL4 & & -0.877 & -0.925 & 0.103 & $<0.001$ & 1.022 & 2.125 & 0.060 & $<0.001$ \\
\hline REL5 & & 0.668 & 0.456 & 0.051 & $<0.001$ & 0.914 & 1.228 & 0.028 & $<0.001$ \\
\hline LA1 & LA & 0.482 & 1 & - & - & -0.326 & -0.372 & 0.013 & $<0.001$ \\
\hline LA2 & & 0.963 & 6.52 & 0.588 & $<0.001$ & -1.507 & -5.607 & 0.399 & $<0.001$ \\
\hline LA3 & & 0.974 & 7.802 & 0.888 & $<0.001$ & -1.515 & -6.669 & 0.642 & $<0.001$ \\
\hline LA4 & & 0.936 & 4.839 & 0.358 & $<0.001$ & -1.468 & -4.172 & 0.195 & $<0.001$ \\
\hline SV1 & VS & 0.96 & 1 & - & - & 0.121 & 0.429 & 0.043 & $<0.001$ \\
\hline SV2 & & 0.971 & 1.182 & 0.088 & $<0.001$ & 0.133 & 0.553 & 0.055 & $<0.001$ \\
\hline SV3 & & 0.843 & 0.459 & 0.025 & $<0.001$ & -0.261 & -0.485 & 0.020 & $<0.001$ \\
\hline SV4 & & 0.821 & 0.421 & 0.023 & $<0.001$ & -0.071 & -0.125 & 0.018 & $<0.001$ \\
\hline $\mathrm{AB} 1$ & $\mathrm{AB}$ & 0.934 & 1 & - & - & -0.263 & -0.737 & 0.037 & $<0.001$ \\
\hline $\mathrm{AB} 2$ & & 0.915 & 0.867 & 0.037 & $<0.001$ & -0.187 & -0.463 & 0.028 & $<0.001$ \\
\hline AB3 & & 0.9 & 0.79 & 0.032 & $<0.001$ & -0.144 & -0.331 & 0.025 & $<0.001$ \\
\hline AB4 & & 0.93 & 0.963 & 0.042 & $<0.001$ & 0.408 & 1.107 & 0.035 & $<0.001$ \\
\hline AB5 & & 0.992 & 2.989 & 0.271 & $<0.001$ & 0.525 & 4.148 & 0.353 & $<0.001$ \\
\hline AB6 & & 0.995 & 3.762 & 0.493 & $<0.001$ & 0.527 & 5.226 & 0.665 & $<0.001$ \\
\hline PN1 & PN & 0.975 & 1 & - & - & 0.006 & 0.026 & 0.047 & 0.574 \\
\hline PN2 & & 0.969 & 0.903 & 0.054 & $<0.001$ & 0.037 & 0.149 & 0.043 & $<0.001$ \\
\hline PN3 & & 0.964 & 0.824 & 0.046 & $<0.001$ & -0.137 & -0.510 & 0.041 & $<0.001$ \\
\hline PN4 & & 0.952 & 0.71 & 0.038 & $<0.001$ & -0.165 & -0.539 & 0.036 & $<0.001$ \\
\hline PN5 & & 0.851 & 0.371 & 0.02 & $<0.001$ & 0.233 & 0.445 & 0.021 & $<0.001$ \\
\hline
\end{tabular}

Source: (Montesinos-López et al. 2016).

\subsubsection{Model fit (by regions) with the MGCFA}

First was tested whether the proposed 11-factor model fits the empirical data from each region. The results show a good model fit for the 8 regions. In Mexico City the fit was appropriate since the indices obtained were: CFI $=$ $0.993(>0.96)$, TLI $=0.993(>0.96)$ and RMSEA $=0.053(<0.06)$. Also, in the South Central region the fit was appropriate $[\mathrm{CFI}=0.979(>0.96), \mathrm{TLI}=0.978(>0.96)$ and $\mathrm{RMSEA}=0.054(<0.06)]$. The same was observed in the North Central region [CFI $(0.990>0.96)$, TLI $(0.989>0.96)$ and RMSEA $(0.051<0.06)]$. Also, the proposed model was supported in the Northeastern regions $[\mathrm{CFI}=0.991(>0.96)$, TLI $=0.990(>0.96)$ and RMSEA $=$ $0.048(<0.06)]$, Western region $[\mathrm{CFI}=0.994(>0.96), \mathrm{TLI}=0.994(>0.96)$ and $\mathrm{RMSEA}=0.05(<0.06)]$, South region $[\mathrm{CFI}=0.990(>0.96), \mathrm{TLI}=0.989(>0.96)$ and $\mathrm{RMSEA}=0.049(<0.06)]$, Center region $[\mathrm{CFI}=0.989$ $(>0.96)$, TLI $=0.988(>0.96)$ and RMSEA $=0.05(<0.06)]$ and Northwest region $[\mathrm{CFI}=0.992(>0.96)$, TLI $=$ $0.992(>0.96)$ and RMSEA $=0.055(<0.06)]$.

Table 4 shows the estimated factor loadings and thresholds for multi-group model by regions. In this case all factor loadings were statistically significant and only one of the thresholds turned out to be not significant (PN1 with a p-value $=0.580$ ). The factor with largest estimated variances were: SV and PN with 13.732 and 14.433, 
respectively, while the factors with the lowest estimated variances were: AGT and LA with 0.891 and 0.304 respectively. In case of the covariance's three were not significant. These values correspond to the pairs; PR-REL, ATT-REL and REL-LA. All of these have correlations less than 0.03 in absolute value. The range of the observed correlations is between -0.556 and 0.813 . The higher and positive correlations $(>0.75)$ corresponds to factor pairs: SV-AB (0.767), SV-PN (0.776), PB-AGT (0.813), AGT-SV (0.788) and AGT-PN (0753). Such correlations were also reported in the global model and have the same interpretation. In the case of the negative correlations with higher negative values $(<-0.5)$; they correspond to the factor pairs: PB-PR, PR-AGT, PR-AB and PR-PN with $-0.525,-0.556,-0.501$ and -0.524 , respectively.

Table 4. Estimates of factor loadings and thresholds for the multi-group model at national level (by region)

\begin{tabular}{|c|c|c|c|c|c|c|c|c|c|}
\hline \multirow{2}{*}{ Indicator } & \multirow{2}{*}{ Factor } & \multirow{2}{*}{ Standardized loads } & \multicolumn{3}{|c|}{ Non-standardized loads } & \multirow{2}{*}{ Standardized thresholds } & \multicolumn{3}{|c|}{ Non-standardized thresholds } \\
\hline & & & Value & S.E. & p-value & & Value & S.E. & p-value \\
\hline KN1 & \multirow{8}{*}{$\mathrm{KN}$} & 0.912 & 1.000 & - & - & 0.219 & 0.532 & 0.027 & $<0.001$ \\
\hline $\mathrm{KN} 2$ & & 0.869 & 0.792 & 0.024 & $<0.001$ & 0.664 & 1.342 & 0.029 & $<0.001$ \\
\hline KN3 & & 0.971 & 1.832 & 0.077 & $<0.001$ & 0.309 & 1.291 & 0.060 & $<0.001$ \\
\hline KN4 & & 0.970 & 1.804 & 0.074 & $<0.001$ & 0.354 & 1.457 & 0.064 & $<0.001$ \\
\hline KN5 & & 0.858 & 0.755 & 0.022 & $<0.001$ & 0.643 & 1.253 & 0.027 & $<0.001$ \\
\hline KN6 & & 0.865 & 0.778 & 0.023 & $<0.001$ & 0.230 & 0.458 & 0.022 & $<0.001$ \\
\hline KN7 & & 0.731 & 0.483 & 0.014 & $<0.001$ & 0.115 & 0.169 & 0.015 & $<0.001$ \\
\hline $\mathrm{KN} 8$ & & 0.614 & 0.351 & 0.012 & $<0.001$ & 0.869 & 1.100 & 0.017 & $<0.001$ \\
\hline KN9 & \multirow{7}{*}{$\mathrm{TR}$} & 0.639 & 0.375 & 0.012 & $<0.001$ & 0.664 & 0.863 & 0.016 & $<0.001$ \\
\hline TR1 & & 0.940 & 1.000 & - & - & 0.026 & 0.076 & 0.030 & 0.012 \\
\hline TR2 & & 1.000 & 20.162 & 0.089 & $<0.001$ & -0.058 & -3.206 & 0.564 & $<0.001$ \\
\hline TR3 & & 0.946 & 1.058 & 0.036 & $<0.001$ & 0.293 & 0.904 & 0.039 & $<0.001$ \\
\hline TR4 & & 0.895 & 0.727 & 0.023 & $<0.001$ & 0.086 & 0.192 & 0.024 & $<0.001$ \\
\hline TR5 & & 0.922 & 0.862 & 0.030 & $<0.001$ & 0.038 & 0.097 & 0.027 & $<0.001$ \\
\hline TR6 & & 0.958 & 1.206 & 0.053 & 0.000 & 0.337 & 1.171 & 0.054 & $<0.001$ \\
\hline PB1 & \multirow{6}{*}{ PB } & 0.850 & 1.000 & - & - & 0.294 & 0.558 & 0.022 & $<0.001$ \\
\hline PB2 & & 0.925 & 1.503 & 0.053 & $<0.001$ & 0.329 & 0.863 & 0.036 & $<0.001$ \\
\hline PB3 & & 0.729 & 0.659 & 0.020 & $<0.001$ & -0.337 & -0.491 & 0.016 & $<0.001$ \\
\hline PB4 & & 0.850 & 0.999 & 0.032 & $<0.001$ & 0.120 & 0.228 & 0.020 & $<0.001$ \\
\hline PB5 & & 0.925 & 1.503 & 0.053 & $<0.001$ & 0.335 & 0.878 & 0.035 & $<0.001$ \\
\hline PB6 & & 0.756 & 0.715 & 0.021 & $<0.001$ & 0.151 & 0.231 & 0.016 & $<0.001$ \\
\hline PB7 & \multirow{7}{*}{ PR } & 0.933 & 1.605 & 0.060 & $<0.001$ & 0.400 & 1.110 & 0.042 & $<0.001$ \\
\hline PR1 & & 0.895 & 1.000 & - & - & -0.297 & -0.668 & 0.028 & $<0.001$ \\
\hline PR2 & & 0.899 & 1.021 & 0.038 & $<0.001$ & -0.109 & -0.250 & 0.024 & $<0.001$ \\
\hline PR3 & & 0.939 & 1.360 & 0.055 & $<0.001$ & -0.172 & -0.501 & 0.033 & $<0.001$ \\
\hline PR4 & & 0.955 & 1.595 & 0.067 & $<0.001$ & -0.243 & -0.816 & 0.042 & $<0.001$ \\
\hline PR5 & & 0.930 & 1.261 & 0.049 & $<0.001$ & -0.112 & -0.306 & 0.029 & $<0.001$ \\
\hline PR6 & & 0.963 & 1.775 & 0.086 & $<0.001$ & -0.357 & -1.325 & 0.063 & $<0.001$ \\
\hline ATT1 & \multirow{5}{*}{ ATT } & 0.894 & 1.000 & - & - & -1.331 & -2.964 & 0.118 & $<0.001$ \\
\hline ATT2 & & 0.991 & 3.677 & 1.682 & 0.029 & -1.138 & -8.404 & 3.567 & 0.018 \\
\hline ATT3 & & 0.854 & 0.826 & 0.052 & $<0.001$ & -0.819 & -1.576 & 0.049 & $<0.001$ \\
\hline ATT4 & & -0.069 & -0.035 & 0.009 & $<0.001$ & -0.429 & -0.430 & 0.011 & $<0.001$ \\
\hline ATT5 & & 0.779 & 0.625 & 0.039 & $<0.001$ & -0.672 & -1.073 & 0.030 & $<0.001$ \\
\hline AGT1 & \multirow{5}{*}{ AGT } & 0.686 & 1.000 & - & - & -0.278 & -0.382 & 0.015 & $<0.001$ \\
\hline AGT2 & & 0.916 & 2.415 & 0.076 & $<0.001$ & 0.181 & 0.450 & 0.028 & $<0.001$ \\
\hline AGT3 & & 0.973 & 4.426 & 0.245 & $<0.001$ & 0.147 & 0.632 & 0.054 & $<0.001$ \\
\hline AGT4 & & 0.821 & 1.525 & 0.046 & $<0.001$ & 0.582 & 1.020 & 0.023 & $<0.001$ \\
\hline AGT5 & & 0.837 & 1.624 & 0.048 & $<0.001$ & 0.521 & 0.954 & 0.024 & $<0.001$ \\
\hline AGT6 & \multirow{5}{*}{ REL } & 0.965 & 3.901 & 0.211 & $<0.001$ & 0.362 & 1.380 & 0.075 & $<0.001$ \\
\hline REL1 & & 0.923 & 1.000 & - & - & 0.778 & 2.022 & 0.168 & $<0.001$ \\
\hline REL2 & & 0.866 & 0.723 & 0.074 & $<0.001$ & 1.305 & 2.612 & 0.052 & $<0.001$ \\
\hline REL3 & & 0.991 & 3.146 & 0.944 & 0.001 & 1.114 & 8.481 & 2.315 & $<0.001$ \\
\hline REL4 & & 0.850 & 0.673 & 0.068 & 0.000 & 1.019 & 1.936 & 0.037 & $<0.001$ \\
\hline
\end{tabular}




\begin{tabular}{|c|c|c|c|c|c|c|c|c|c|}
\hline REL5 & & 0.793 & 0.542 & 0.063 & $<0.001$ & 0.912 & 1.496 & 0.039 & $<0.001$ \\
\hline LA1 & \multirow{3}{*}{ LA } & 0.483 & 1.000 & - & - & -0.324 & -0.371 & 0.013 & $<0.001$ \\
\hline LA2 & & 0.980 & 8.953 & 1.205 & $<0.001$ & -1.499 & -7.555 & 0.916 & $<0.001$ \\
\hline LA3 & & 0.966 & 6.819 & 0.615 & $<0.001$ & -1.505 & -5.859 & 0.412 & $<0.001$ \\
\hline LA4 & \multirow{5}{*}{$\mathrm{SV}$} & 0.952 & 5.637 & 0.442 & $<0.001$ & -1.460 & -4.771 & 0.261 & $<0.001$ \\
\hline SV1 & & 0.965 & 1.000 & - & - & 0.121 & 0.463 & 0.047 & $<0.001$ \\
\hline SV2 & & 1.000 & 10.684 & 0.239 & $<0.001$ & 0.161 & 6.373 & 0.392 & $<0.001$ \\
\hline SV3 & & 0.851 & 0.437 & 0.026 & $<0.001$ & -0.258 & -0.492 & 0.021 & $<0.001$ \\
\hline SV4 & & 0.829 & 0.399 & 0.024 & $<0.001$ & -0.073 & -0.130 & 0.019 & $<0.001$ \\
\hline $\mathrm{AB} 1$ & \multirow{5}{*}{$\mathrm{AB}$} & 0.941 & 1.000 & - & - & -0.264 & -0.779 & 0.041 & $<0.001$ \\
\hline AB2 & & 0.924 & 0.869 & 0.039 & $<0.001$ & -0.186 & -0.486 & 0.030 & $<0.001$ \\
\hline AB3 & & 0.906 & 0.772 & 0.033 & $<0.001$ & -0.145 & -0.343 & 0.026 & $<0.001$ \\
\hline AB4 & & 0.934 & 0.942 & 0.042 & $<0.001$ & 0.406 & 1.138 & 0.036 & $<0.001$ \\
\hline AB5 & & 0.999 & 9.608 & 2.411 & $<0.001$ & 0.528 & 14.111 & 3.474 & $<0.001$ \\
\hline AB6 & \multirow{6}{*}{$\mathrm{PN}$} & 0.999 & 9.756 & 2.277 & $<0.001$ & 0.531 & 14.420 & 3.296 & $<0.001$ \\
\hline PN1 & & 0.967 & 1.000 & - & - & 0.006 & 0.023 & 0.041 & 0.580 \\
\hline PN2 & & 1.000 & 19.587 & 0.076 & $<0.001$ & 0.026 & 1.936 & 0.768 & 0.012 \\
\hline PN3 & & 0.963 & 0.934 & 0.040 & $<0.001$ & -0.135 & -0.498 & 0.040 & $<0.001$ \\
\hline PN4 & & 0.953 & 0.829 & 0.035 & $<0.001$ & -0.167 & -0.552 & 0.037 & $<0.001$ \\
\hline PN5 & & 0.856 & 0.436 & 0.018 & $<0.001$ & 0.232 & 0.448 & 0.021 & $<0.001$ \\
\hline
\end{tabular}

Source: (Montesinos-López et al. 2016).

\subsection{Configural Invariance}

Due to the good fit of the 11-factor structure for each group earlier, one could expect that configural invariance would be supported and the fit indexes confirmed this. Table 5 shows that Model 1 provided a good fit to the data (CFI, TLI and RMSEA yielded satisfactory values: $0.991,0.99$ and 0.055 , respectively) indicating that there is evidence the factorial structure of the construct is equal across regions. All this also was supported by $\triangle \mathrm{CFI}$ criteria which support configural invariance when the $\Delta \mathrm{CFI}<0.01$.

\subsection{Invariance of Factorial Loadings, Thresholds and Intercept}

Since we found evidence of configural invariance of the factors among regions, we continued to seek evidence to identify the invariance of factor loadings and thresholds among regions. According with the fit indices CFI, TLI and RMSEA we have a good fit $(0.990,0.990$ and 0.056 respectively). Also, in this case the $\Delta C F I=0.001$ $(<0.01)$ index provided evidence in favor loadings of the factor and thresholds (Table 5).

Table 5. Fit indices to assess the invariance of the instrument (by region).

\begin{tabular}{lllll}
\hline & CFI & TLI & RMSEA & ACFI \\
\hline $\begin{array}{l}\text { Configurational (Model 1) } \\
\text { Loadings and Intercept / Threshold (Models }\end{array}$ & 0.991 & 0.990 & 0.055 & - \\
$\begin{array}{l}\text { 2 and 3) } \\
\begin{array}{l}\text { Error variance (Model 4) } \\
\text { Latent variance and covariance (Models 5 }\end{array}\end{array}$ & 0.990 & 0.990 & 0.056 & 0.001 \\
and 6) & 0.980 & 0.980 & 0.078 & 0.008 \\
\hline
\end{tabular}

Source: (Montesinos-López et al. 2016).

\subsection{Invariance of Co-Variance Error}

Invariance of co-variance error between regions also is reasonable since we got a good fit for CFI, TLI and RMSEA (0.988, 0.988 and 0.061respectively) (Table 5). Also, according with the $\Delta \mathrm{CFI}=0.002(<0.01)$ index gives evidence in favor of invariance of co-variance error, implying Covariance's) of errors are invariant between regions (Table 5).

\subsection{Latent Variance and Invariance of Covariance's}

Since we have shown that it is satisfied the assumption of invariance of the (co)variance's between regions, here we tested the latent variance and invariance of covariance's. Also, this invariance assumption is reasonable since 
we got that the CFI, TLI and RMSEA had values of $0.9800,0.980$ and 0.078 respectively (Table 5). Also, this invariance between regions is supported with the $\Delta$ CFI index $(0.008<0.01)$.

Next for testing the model 7 (factor mean invariance) we performed a regression analysis for each factor and we used the items of each factor as dependent variable in a logistic regression and regions as independent variable. This testing was done in this way also to get a better understanding of the perceptions and attitudes toward the production and consumption of GMOs between regions.

\subsection{Latent Mean Comparison between Regions}

Knowledge. According to a logistic regression performed for each of the items of this factor we not found significant differences between regions. However, we observed a low knowledge since the percentages of "yes" for these items ranges between $25 \%$ and $45 \%$.

Trust. Only item TR3 was significant according to a logistic regression between regions and the South central region have the lowest levels of trust in this indicator, while Northwest and Northeastern are the regions with the highest levels. In general, the trust is low since most items ranges between $35 \%$ and $45 \%$.

Perceived Benefits. Except for PB3 item, percentages mostly take values between $30 \%$ and $48 \%$, these values show homogeneous pattern and also the variable region was not significant for any of the items of this latent factor perceived benefits. Notably, the BP3 although is homogeneous indicator between regions has the highest percentages, in all regions (See Figure 2).

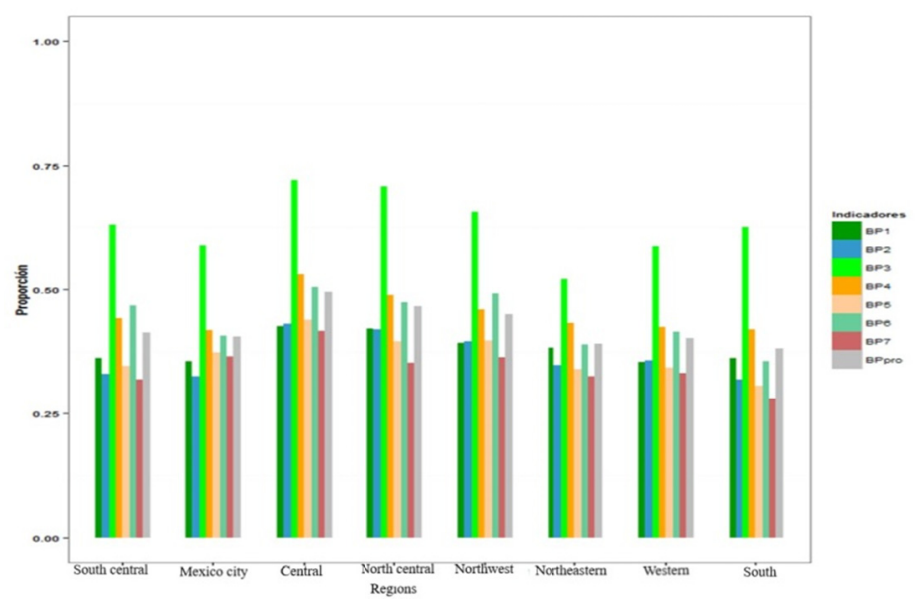

Figure 2. Benefits on GMOs by region

Source: (Montesinos-López et al. 2016).

Perceived Risks. According to the regression results, the region only was significant for the item (PR3) in this latent factor. In general people surveyed perceive high risk (percentages $>50 \%$ ). In Figure 3, we can see that for item PR3 the South central region has the largest proportions while the Northeastern and Northwest regions had the smallest proportions, but in all regions percentages are greater than $50 \%$. 


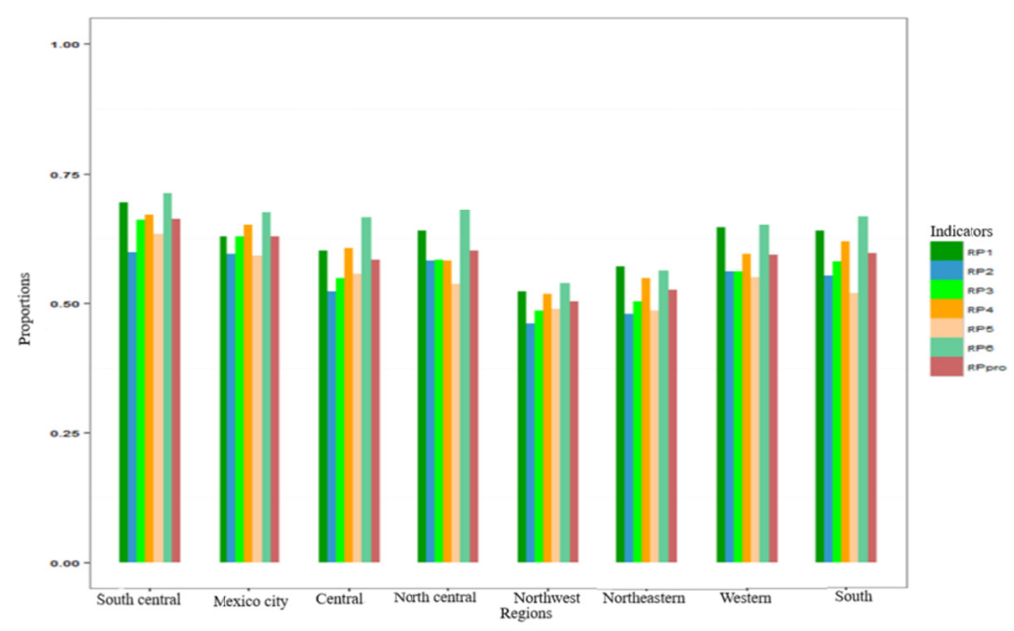

Figure 3. Perceived risk on GMOs by region

Source: (Montesinos-López et al. 2016).

Attitude towards technology. We did not find statistical significance for any of the items of this factor between regions. Higher percentages were observed $(>63 \%)$ for all items in all regions, this indicates that people have a fairly positive attitude towards technology in all regions.

Attitude towards gene technology. The proportions observed for this factor are relatively small except for item ATG1 and contrast with the many positive results towards the attitude towards technology. The percentages for most items are between 25 and 50\% (Figure 4) and no significant differences between regions were found.

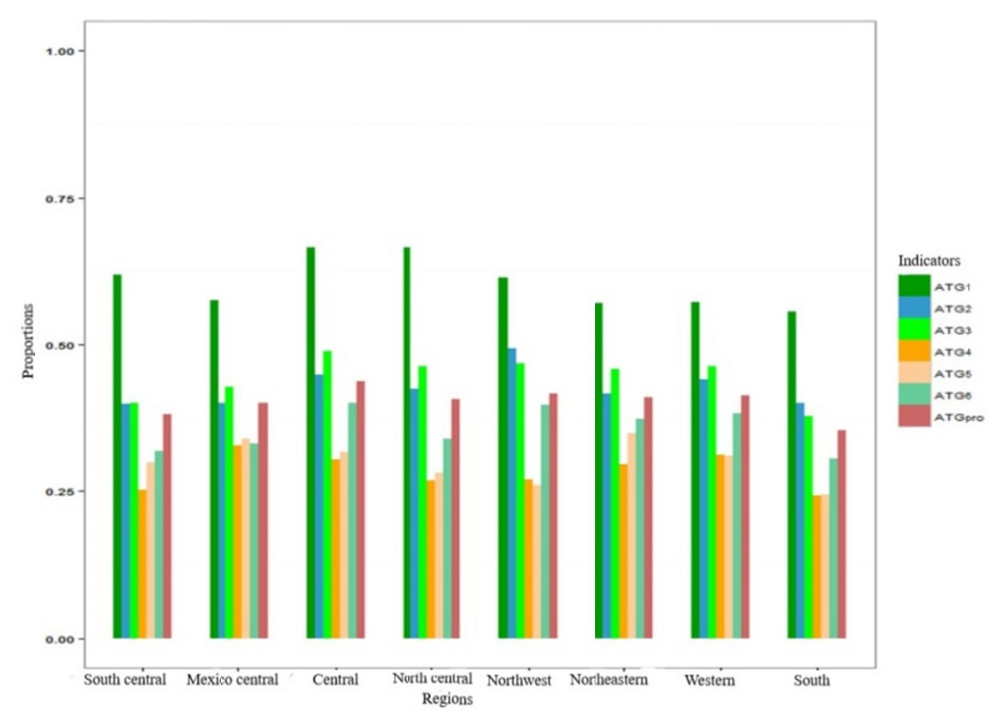

Figure 4. Attitude towards gene technology on GMOs by region

Source: (Montesinos-López et al. 2016).

Religion. All items have considerably small and similar percentages $(<25 \%)$ across regions and not significant differences were found between regions.

Labelling. No significant differences were found between regions in all items of this factor, but the surveyed people agree with the labelling of transgenic products (percentages $>90 \%$ for all items except item LA1 that shows that only $63 \%$ of people read the labels of products).

Social values. According to the logistic regression performed only item SV1 was statistically different between regions. The northwestern region has a higher proportion than the other regions (53\%), while Mexico City has 
the smallest percentage (about 38\%). Items SV3 and SV4 shows percentages largest tan 50\% while the rest of items the percentages are lower than $50 \%$ across regions.

Attitude towards buying. No significant differences between regions was found for all items. However, people would buy GM products if they have less fat, they are cheaper and grown in similar environmental conditions than conventional products ( $>50 \%$ ) (Figure 5). Also, Figure 5 shows that in all regions lower percentages are observed in items $\mathrm{AB} 4, \mathrm{AB} 5$ and $\mathrm{AB} 6$, that means that they will not buy transgenic prodlucts when the price are equal to conventional products.

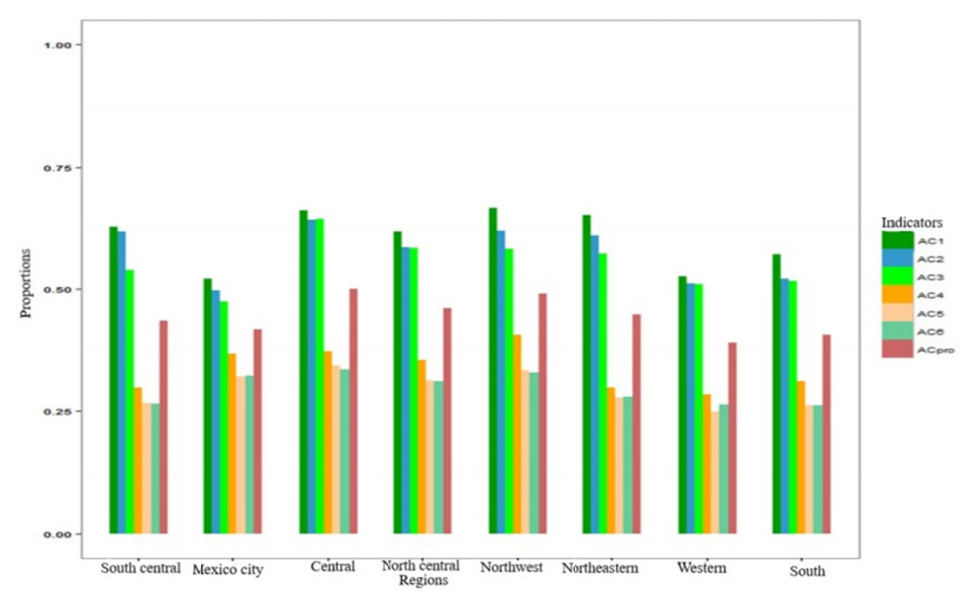

Figure 5. Attitude towards buying of GMOs by region.

Source: (Montesinos-López et al. 2016).

Promotion. Here 3 items (PR1, PR2 and PR3) were statistically significant between regions. In PR1 the regions center, north central, northeastern and northwestern regions have percentages greater than $50 \%$. While in PR2 the regions with the largest percentages were center and northwestern with percentages larger than $50 \%$. In PR3 with the exception of Mexico City all regions have percentages larger than $50 \%$. With the logistic regression performed for each item using as independent variable the region, there are elements to no support the hypothesis of homogeneity of factor means between regions, since the levels of each factor were statistically significant between regions for some items.

\section{Discussions and Conclusions}

In this paper we developed an instrument to measuring perceptions and attitudes towards the production and consumption of GMOs in the Mexican urban population. This measurement instrument is composed of the following eleven factors: knowledge, trust, perceived benefits, perceived risks, attitude towards technology, attitude towards religion, societal values, labeling, gene technology, promotion and attitudes towards buying. This instrument was built after an extensive literature review of studies to measure perceptions and attitudes towards GMOs around the world. However, it is original since the number of factors taken into account is different to the existing measurement instruments, additionally all the items proposed are binary and are specific for the Mexican urban population. The first formal version of the instrument was composed of 11 factors and 60 items and was tested with 1000 people in Colima, México, and after minor corrections of this instrument we ended up with a version of 11 factors and 63 items which was applied to a probabilistic sample of 14,720 Mexican individuals aged between 18 to 65 years of urban areas across México. Then, we proceed to the validation of the proposed instrument using CFA for binary data. The method of estimation used a probit link with weighted least squares.

According with the CFA analysis performed we found elements to say that the proposed instrument given in Figure 1 and Table 2 is reasonable to measure the perceptions and attitudes of the Mexican urban population on the production and consumption of GMOs and the final dichotomous instrument is composed of sixty-three items and eleven latent factors. Also, with the performed CFA for multi-groups (Multiple Groups Model by Regions and MIMIC by Regions) we have elements to assume that the proposed measurement instrument also is valid for each of the regions of Mexico under study, that is, the instrument measures the same phenomena in the 8 regions under study. Also, according with the analysis and correlations observed we found strong relationships between some factors. For example, high perceived benefits are associated with a positive attitude towards gene 
technology, high societal values and a positive attitude towards labeling. On the other extreme, we found that high perceived risks are associated with low perceived benefits, a negative attitude towards gene technology and a negative attitude towards the promotion.

Regarding items of each factor measured in different regions, a similar pattern among them were observed. In the case of knowledge factor, a general lack of such factor was observed, not only in the GMOs definition, but also in their applications, and its laws and regulations. With respect to the trust factor, its result was low $(<50 \%)$, however Mexican people have greater trust for universities and scientists than for pharmaceutical companies working with transgenic products. As for benefits and perceived risks, Mexicans perceive high risk in the use of transgenic products. Most individuals in all regions consider that the use of GMOs can bring consequences which range from several diseases and environmental damage that can produce adverse effects on future generations. Nevertheless, excepting gene technology, test-takers have a positive attitude towards science and technology as they consider both are vital for social development.

In the case of the religion factor, surveyed people are not agree with GMOs production, in fact, they do consider immoral plants and animals modifications. With regard to the labelling, it was observed that only $63 \%$ of test-takers read labels on the products they consume. Additionally, they show a positive attitude towards the need to label genetically modified products. Meanwhile, surveyed people showed preference to buy GMOs product only if such products are cheaper, with low fat content, and have been grown in similar environmental conditions as organic products. If prices are similar, participants prefer to buy organic products such as maize and beans. However, they are not agree, about the use of technology to produce transgenic produces for human consumption, even that they recognize the GMOs potential, but they disagree with their application.

Finally, with regard to promotion, a slightly positive attitude among surveyed people was observed, toward that the Mexican government provide funding for research with transgenic products to generate new drugs. However, participants showed their disagreement about that the government could fund private companies to produce transgenic products in Mexico or to import these products for consumption. Also, it is important to point out that the proposed instrument is very important to measure the perceptions and attitudes of the Mexican population and we hope can be used for future studies since can measure 11 latent factors really important to have a clear picture of these perceptions and attitudes.

\section{Acknowledgements}

\section{CONSEJO NACIONAL DE CIENCIA Y TECNOLOGIA (CONACYT).}

\section{Funding}

CONSEJO NACIONAL DE CIENCIA Y TECNOLOGIA (CONACYT). Project: 000000000233174. Percepciones y actitudes de la población urbana mexicana sobre la producción y consumo de los organismos genéticamente modificados.

\section{References}

Bardin, B., Perrissol, S., Facca, L., \& Smeding, A. (2017). From risk perception to information selection and not the other way round: Selective exposure mechanisms in the field of genetically modified organisms. Food Quality and Preference, 58, 10-17. http://dx.doi.org/10.1016/j.foodqual.2016.12.015

Browne, M. W., \& Cudeck, R. (1993). Alternative ways of assessing model fit. In Bollen, K. A. and Long, J. S. (Eds.), Testing Structural Equation Models (pp. 136-162). Beverly Hills, CA: Sage. https://doi.org/10.1177/0049124192021002005

Cheung, G. W., \& Rensvold, R. B. (2002). Evaluating goodness-of-fit indexes for testing measurement invariance. Structural Equation Modeling, 9(2), 233-255.

Cochran, W. G. (1990). Técnicas de muestreo. México: Compañía Editorial Continental.

Costa-Font, M., \& Gil, J. M. (2009). Structural equation modelling of consumer acceptance of genetically modified (GM) food in the Mediterranean Europe: A cross country study. Food Quality and Preference, 20(6), 399-409.

Eurobarometer. (2010). Food-related risks. Belgium: TNS Opinion \& Social at the request of the European Food Safety Authority (EFSA).

Gatto, K., \& Smoller, M. (2018). Consumer knowledge about food production systems and their purchasing behavior. Environment, Development and Sustainability, 20(6), 2871-2881. https://doi.org/10.1007/s10668-017-0021-y 
Herodotou, C., Kyza, E. A., Nicolaidou, I., Hadjichambis, A., Kafouris, D., \& Terzian, F. (2012). The development and validation of the GMOAS: A questionnaire measuring secondary students' attitudes towards Genetically Modified Organisms. International Journal of Science Education, Part B, 2(2), $131-147$.

Hilbeck, A., Binimelis, R., Defarge, N., Steinbrecher, R., Székács, A., Wickson, F., \& Wynne, B. (2015). No scientific consensus on GMO safety. Environmental Sciences Europe, 1-6. https://doi.org/10.1186/s12302-014-0034-1

Hu, L., \& Bentler, P. M. (1999). Cutoff criteria for fit indexes in covariance structure analysis: Conventional criteria versus new alternatives. Structural Equation Modeling, 6(1), 1-55. https://doi.org/10.1080/10705519909540118.

International Service for the Acquisition of Agri-biotech Applications (ISAAA). (2017). Global Status of Commercialized Biotech/GM Crops in 2017. Global Status of Commercialized Biotech/GM Crops in 2017: The International Service for the Acquisition of Agri-biotech Applications (ISAAA). New York.

Kamle, M., Kumar, P., Patra, J. K., \& Bajpai, V. K. (2017). Kamle, M., Kumar, P., Patra, J. K. \& Bajpai, V. K., (2017). Current perspectives on genetical-ly modified crops and detection methods. https://doi.org/10.1007/s13205-017-0809-3

Kimani, C., \& Zennah, K. (2019). Potential Uses, Perceptions and Policy Issues of Genetically Modified Crops in Africa: A Case Study of Kenya. African Journal of Food Agriculture Nutrition and Development, 19(1), 13946-13958.

Kismiantini, Montesinos-López, O. A., García, J. J., \& Franco-Pérez, E. (2014). Analyzing the Factors of Job Satisfaction in a Mexican Hospital with Binary Indicators by Confirmatory Factor Analysis. International Journal of Business and Management, 9(8), 61-83. https://doi.org/10.5539/ijbm.v9n8p61

Kline, R.B. (2011). Principles and practice structural equation modeling. New York, NY: The Guilford Press.

Landrum, A. R., Hallman, W. K., \& Jamieson, K. H. (2019). Examining the Impact of Expert Voices:Communicating the Scientific Consensus on Genetically-modified Organisms, Environmental Communication. Environmental Communication, $\quad$ 13(1), http://dx.doi.org/10.1080/17524032.2018.1502201

Ma, Y. (2015). Consumers' Different Attitudes towards Genetically Modified Food in the United States and China. Studies in Asian Social Science, 2(2), 1-7.

McDonald, R. P. (1989). An index of goodness-of-fit based on noncentrality. Journal of classification, 6(1), 97-103.

Montesinos-López, O. A., Franco-Pérez, E., Luna-Espinoza, I., \& Aragón-Cuevas, F. (2016). Percepciones y actitudes hacia los transgénicos en México (1st ed., Vol. 1). México: Pearson. Recuperado el 26 de junio de 2019

Olaiz-Fernández, G., Rivera-Dommarco, J., Shamah-Levy, T., Rojas, R., Villalpando-Hernández, S., Hernández-Avila, M., \& Sepúlveda-Amor, J. (2006). Encuesta Nacional de Salud y Nutrición 2006. Cuernavaca, México: Instituto Nacional de Salud Pública.

Pino, G., Amatulli, C., De Angelis, M., \& Peluso, A. M. (2016). The influence of corporate social responsibility on consumers' attitudes and intentions toward genetically modified foods: evidence from Italy. Journal of Cleaner Production, 112, 2861-2869.

Pollack, A. (2016). Genetically engineered crops are safe, analysis finds. The New York Times. Retrieved from https://www.nytimes.com/2016/05/18/business/genetically-engineered-crops-are-safe-analysis-finds.html

R-Core Team. (2019). R: A language and environment for statistical computing. R Foundation for Statistical Computing, Vienna, Austria.

Reséndiz-Ramírez, Z., López-Santillán, J. A., Briones-Encinia, F., Mendoza-Castillo, M. D., \& Varella-Fuentes, S. F. (2014). Situación actual de los sistemas de producción de grano de maíz en Tamaulipas. Investigación y Ciencia, 62(22), 69-75. Retrieved from http://www.redalyc.org/articulo.oa? $\mathrm{id}=67432507009$

Rosseel, Y. (2012). Lavaan: An R package for structural equation modeling. Journal of Statistical Software, 48(2), 1-36

Sánchez, R., \& Echeverri, J. (2004). Validación de escalas de medición en salud. Rev Salud Pública-Bogotá, 6(3), 
$302-18$.

Sorgo, A., \& Ambrozic-Dolinsek, J. (2010). Knowledge of, attitudes toward, and acceptance of genetically modified organisms among prospective teachers of biology, home economics, and grade school in Slovenia. Biochemistry and Molecular Biology Education, 38(3), 141-150.

Sorgo, A., Ambrozic-Dolinsek, J., Usak, M., \& Özel, M. (2011). Knowledge about and acceptance of genetically modified organisms among pre-service teachers: a comparative study of Turkey and Slovenia. Electronic Journal of Biotechnology, 14(4), 5-5.

Steiger, J. H. (1989). EzPATH: Causal Modeling. Evanston: Systat.

Steiger, J. H., \& Lind, J. C. (1980, May). Statistically based tests for the number of common factors. In annual meeting of the Psychometric Society, Iowa City, IA (Vol. 758).

Stroup, W. W. (2012). Generalized linear mixed models: modern concepts, methods and applications. Boca Raton: CRC Press.

Suhr, D. D. (2006). Exploratory or confirmatory factor analysis? (pp. 1-17). SAS Institute.

Vandenberg, R. J., \& Lance, C. E. (2000). A review and synthesis of the measurement invariance literature: Suggestions, practices, and recommendations for organizational research. Organizational Research Methods, 3(1), 4-70.

Wade, T., Tiggemann, M., Heath, A. C., Abraham, S., Treloar, S. A., \& Martin, N. G. (1996). Structure of disordered eating in a twin community sample. International Journal of Eating Disorders, 19(1), 63-71.

Woodfint, R. M., Hamlin, E. \& Lee, K. (2018). Avian Bioreactor Systems: A Review. Molecular Biotechnology, 60(12), 975-983.

Yu, C. Y. (2002). Evaluating cutoff criteria of model fit indices for latent variable models with binary and continuous outcomes (Vol. 30). Los Angeles: University of California, Los Angeles.

Yu, C. Y., \& Muthen, B. (2002). Evaluation of model fit indices for latent variable models with categorical and continuous outcomes. In annual meeting of the American Educational Research Association, New Orleans, LA.

\section{Copyrights}

Copyright for this article is retained by the author(s), with first publication rights granted to the journal.

This is an open-access article distributed under the terms and conditions of the Creative Commons Attribution license (http://creativecommons.org/licenses/by/4.0/). 